\title{
ANÁLISE RÍTMICA APLICADA AO ENTEDIMENTO DE EVENTOS HIDROLÓGICOS EXTREMOS NA BACIA HIDROGRÁFICA DO RIO DAS ANTAS, IRATI - PR
}

\author{
Francieli Kruk ${ }^{(a)}$, Andreza Rocha de Freitas ${ }^{(b)}$ \\ ${ }^{(a)}$ Discente Licenciatura em Geografia, UNICENTRO,frankruk1304@gmail.com \\ (b) Docente, Departamento de Geografia, UNICENTRO, andreza_rocha@yahoo.com.br
}

Eixo: Climatologia em diferentes níveis escalares: mudanças e variabilidades

\begin{abstract}
Resumo
Este trabalho teve como objetivo identificar as causas das precipitações intensas que ocorreram entre os anos de 1983 e 2015, no município de Irati, Paraná, que colaboraram para a ocorrência de eventos hidrológicos extremos, os quais causaram transtornos em pontos específicos do município. Para o entendimento da origem desses fenômenos ocorridos no município, foi adotada a metodologia da Análise Rítmica, utilizando dados de: pressão atmosférica, temperatura, umidade relativa do ar, nebulosidade e direção dos ventos. Os dados foram coletados no websitedo Instituto Nacional de Meteorologia (INMET) e a identificação dos sistemas atmosféricos atuantes na região de pesquisa foi realizada através das cartas sinóticas, disponibilizadas pela Marinha do Brasil. Depois da coleta dos dados, os mesmos foram tabulados para geração dos gráficos, por meio do software RitmoAnálise. No verão observou-se que as causas de precipitações intensas foram em função das chuvas convectivas, típicas na região nesta estação e que provocam uma elevada precipitação em pouco tempo. Outra causa foi o encontro de massas de ar quentes e frias que provocam as chuvas frontais. No inverno se observou que a precipitações resultaram na sua maioria da entrada da Frente Polar Atlântica.
\end{abstract}

Palavras chave:Enchentes, Desastres Naturais, Planejamento Urbano.

\section{Introdução}

Vários problemas são gerados em função da concentração dos habitantes nos espaços urbanos, que em grande parte ocorrem emáreas consideradas de risco a inundações e outros desastres ambientais. Vale apontar que a administração pública autoriza a construção nesses espaços, sendo este o objetivo do trabalho.

Mendonça e Souza (2010, pág. 2) afirmam que "as enchentes não afetariam o homem, mas infelizmente a ocupação de áreas impróprias e o desrespeito aos limites impostos pela natureza e a lei criada pelo próprio semelhante acarreta o caos urbano." Então é indispensável apresentar que essas enchentes e inundações são resultado do processo de urbanização, isso faz parte da história das cidades ao longo dos anos. 
Para Tucci (s/d) a inundação urbana é uma ocorrência muito antiga. A inundação ocorre quando as águas de riachos, rios ou até mesmo galerias saem do leito de escoamento e passam a ocupar áreas que são utilizadas para as moradias, comércios, transportes, indústrias, entre outros.

De acordo com Freitas e Ximenes (2012, p.1) "as enchentes são os desastres naturais com maior frequência e afetam a vida de aproximadamente 102 milhões de pessoas a cada ano, principalmente nos países em desenvolvimento e em grandes centros urbanos, com tendência de aumento nas próximas décadas". Por conseguinte, as enchentes causam transtornos, afetando direta e indiretamente milhares de pessoas todos os anos.

Para ser possível o entendimento desses eventos hidrológicos, foi necessário que se faça a coleta de dados relacionados aos índices pluviométricos da área de estudo. Em vista disso, estudos relacionados ao eventos hidrológicos se tornam importantes, uma vez que possibilita a explicação da geração dessas ocorrências.

É preciso analisar algumas das causas. Uma delas Canal (2011) apresenta sobre as chuvas intensas, as quais, são fenômenos meteorológicos que são definidos por precipitações fortes contínuas e que tenham curta duração. Esses fenômenos são capazes de promover enchentes, particularmente em áreas mais ocupadas, nestas condições, os sistemas que drenam a água precipitada perdem a eficiência, então, o poder de infiltração diminui, enquanto o de escoamento superficial aumenta.

Outro elemento importante para as causas das enchentes, escoamentos e inundações são os sistemas atmosféricos. Há cinco grandes domínios climáticos que atuam em todo o território brasileiro, pois estas porções da atmosfera possuem suas particularidades de umidade, temperatura e pressão, essas que modificam e determinam os tipos climáticos do Brasil, os climas atuantes da região sul são subúmidos e frios, característicos da área estuda.

Para haver o entendimento da origem dos fenômenos meteorológicos, é necessário que este passe a se dar por meio da noção do ritmo, da dinâmica e também da origem. Portanto, é importante analisar todos as causas que podem provocar as enchentes em um determinado local, é necessário entender como se originou, quais foram os intervalos deste fenômeno e também a sua movimentação sobre a área.

SegundoMonteiro (1971) para se tornar possível a constatação do ritmo do clima é preciso separar o tempo cronológico dos estados atmosféricos, pois esses agem em unidades de tempo menores, por exemplo, diárias. $\mathrm{O}$ autor aborda que com uma escala diária já é possível haver uma associação à variação dos elementos do clima, os tipos de clima que acontecem em ocasião aos mecanismos regionais. $\mathrm{O}$ mesmo 
acaba por colocar que os elementos climáticos estão ligados a sua origem, sendo então necessário que a análise seja feita levando em conta a posição no espaço geográfico.

Portanto, este trabalho tem como objetivo utilizar a metodologia desenvolvida por Monteiro (1971) para apresentar as análises rítmicas do tempo do Município de Irati abordando datas catalogadas pela Defesa Civil entre os anos de 1983 e 2015. A análise rítmica possibilitou a compreensão dos fenômenos que podem ter dado origem as intensas e contínuas precipitações que em inundações afetaram alguns pontos do município.

\section{Métodos e procedimentos}

Buscando entender as causas das precipitações intensas ocorridas no Município de Irati desde 1983 até 2015, adotou-se a Análise Rítmica proposta por Monteiro (1971), que visa mostrar de uma maneira individual os tipos de tempo atmosféricos e assim acompanhar os seus ritmos juntamente com o acompanhamento das medidas observadas por uma estação meteorológica. A adoção desta metodologia auxilia no entendimento da variabilidade dos elementos climáticos e assim sendo possível relaciona-los entre si.

Para apresentar a análise rítmica desta pesquisa foram utilizados dados climáticos, retirados do site do INMET, sendo eles pressão atmosférica, umidade relativa do ar, nebulosidade, pluviosidade e direção dos ventos. Para a interpretação das frentes e massas de ar foram utilizadas as cartas sinóticas, essas que são geradas pela Marinha do Brasil. Os gráficos dos elementos climáticos, necessários para à análise rítmica, foram gerados através do softwareRitmo Análise (BORSATO, 2006; BORSATO e BORSATO, 2008).

A área em que foi estudada corresponde à bacia hidrográfica Rio das Antas, localizada no municípios de Irati, Imbituva e Fernandes Pinheiro, no Estado do Paraná. Sendo esta bacia um dos principais corpos hídricos do Município (ANDRADE et al, 2009), sendo que o Rio das Antas tem suas nascentes na serra do Nhapindazal (área rural) e depois de percorrer cerca de 1,5 km adentra o perímetro urbano, mais precisamente na Vila São João. Segundo Freitas (2010) na bacia do Rio das Antas são identificados diversos tipos de usos de terra, como: área urbanizada, cultivo, área industrial, mata, que influenciam diretamente e indiretamente na dinâmica da área.

\section{Resultados}

O trabalho tem como área de estudoso Município de Irati, estado Paraná,amplamente submetido à enchentes ocorrem no seu espaço urbano. Deve-se salientar que no espaço urbano existem taxas menores de permebilização da água no solo. Portanto, pouca água infiltra, tornando mais vulnerável para escoamentos, esses que vão diretos para os canais dos rios, aumento os níveis dos mesmos. 
Entre os anos de 1983 e 2015 foram registrados um total de 16 eventos hidrológicos extremos no Município de Irati, sendo esses com precipitações intensas e contínuas, que aumentaram o nível da água dos canais de drenagem. Os eventos provocaram enxurradas e inundações, causando transtornos à população dos pontos atingidos, principalmente áreas próximas aos canais. Foram escolhidas três datas para serem apresentadas neste relatório. As datas são: dezembro de 1986 (figura 1), abril 2010 (figura2) e julho de 2011 (Figura 3).

Este evento hidrológico ocorreu em dezembro de 1986, entre os dias 14 e 23 . O evento, registrado pela defesa civil, provocou enchentes no municipio de Irati.

Os primeiros elementos a serem analisados foram os de pressão atmosférica e umidade relativa do ar. A pressao atmosférica passou a aumentar no dia 14, permanecendo assim até no dia 19, onde a mesma passou a diminuir do dia 20 até o dia 23. Enquanto a umidade relativa do ar passou a diminuir do dia 14 até o dia 16, voltando a aumentar no dia 17, a qual, sofreu pequenas oscilacoes até o dia 21 e teve uma grande redução no dia 22 ficando assim até no dia seguinte.

Quanto a nebulosidade, o céu ficou encoberto entre os dias 14 a 22, ficando claro apenas no dia 23 onde não houve precipitação. O próximo elemento analisado foi o da direção dos ventos, onde foi verificado que a maioria dos ventos são oriundos de sudoeste, leste e nordeste.Analisando a precipitação foi constatado que precipitou cerca de $202.8 \mathrm{~mm}$, tendo seu ápice no dia 18 onde choveu cerca de $125.1 \mathrm{~mm}$.

Após a análise do gráfico e das cartas sinóticas foi constatado que ocorreram chuvas convectivas, pois, precipitou uma grande quantidade em apenas um dia, e o encontro de massas de ar quentes e frias podem também ter influenciado. 


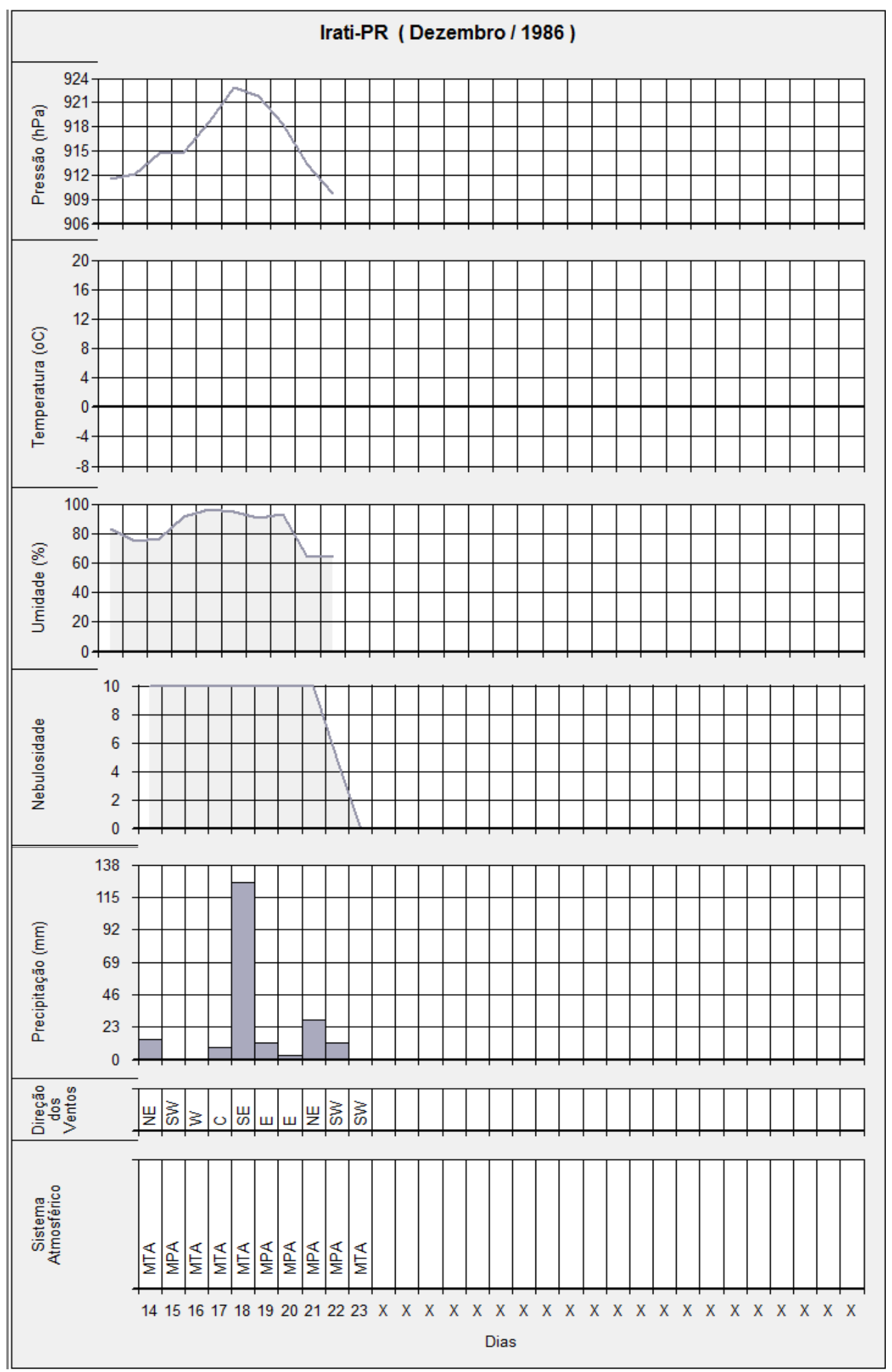




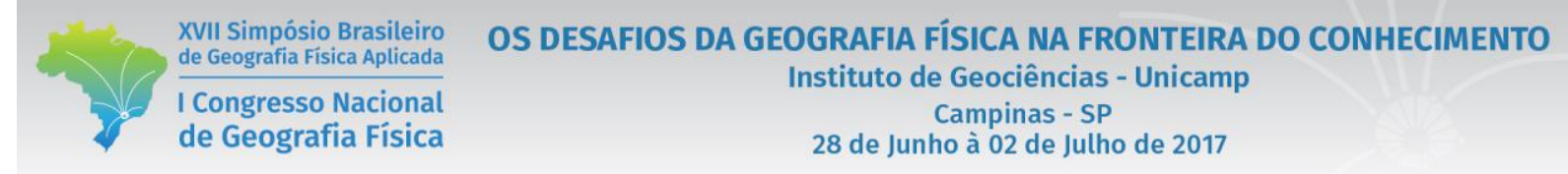

Figura 1 - evento hidrológico, entre os dias 14 e 23 de dezembro do ano de 1986. Figura com dados de Pressão atmosférica ao nível do mar (hPa), Temperatura mínima, média e máxima $\left({ }^{\circ} \mathrm{C}\right)$; umidade relativa do ar $(\%)$; precipitação acumulada em $24 \mathrm{~h}(\mathrm{~mm})$; direção dos ventos e sistemas atmosféricos atuantes no dia (, MPA: Massa Polar Atlântica, MTA: Massa Tropical Atlântica), x: sem data. Fonte: Estação Meteorológica de Observação de Superfície Automática do INMET. Organizado por KRUK (2016).

O evento hidrológico ocorrido em abril de 2010, mais precisamente no dia 26 e foi determinado pela defesa civil como enxurrada, e esta pode ter ocasionado enchentes na região. Entre os dias 21 e 30, houve um índice pluviométrico de $228 \mathrm{~mm}$, e teve uma pluviosidade elevada no dia 23 , onde chegou a chover cerca de $82.4 \mathrm{~mm}$ (Figura 2).

Os primeiros elementos analisados e relacionados foram a temperatura e pressão atmosférica, onde a temperatura a partir do dia 21 passou a baixar e a pressão voltou a subir. No dia 25 a temperatura voltou a subir, enquanto a pressão teve uma diminuição. Logo no dia seguinte a pressão volta a subir, enquanto a temperatura cai chegando numa média de $16.8^{\circ} \mathrm{C}$ no dia 30 .

Relacionando a temperatura, pressão atmosférica e umidade relativa do ar, se verificou que a umidade relativa começou a aumentar no dia 22, onde no dia 24 chegou a 97\%, e a temperatura nesse período diminuiu chegando a $15.4^{\circ} \mathrm{C}$ no mesmo dia, fazendo deste modo a pressão sofrer elevações. No dia 25 a umidade diminuiu um pouco, mas a temperatura volta a elevar permanecendo assim até o dia 27, onde a temperatura diminui e a pressão aumenta. Nos dia 28 e 29 a temperatura sobe, voltando a cair no dia 30, deixando também a umidade relativa mais baixa, e a pressão nesse período aumenta.

Quanto ao maior índice pluviométrico, este foi datado no dia 26, onde chegou a chover cerca de $82.4 \mathrm{~mm}$, fazendo com que a temperatura voltasse a cair.

Outro elemento analisado foi a nebulosidade, que foi relacionada com a precipitação. Entre os dias 22 a 27, e 29 a 30 houve precipitação, então o céu permaneceu encoberto. Nos dias 21 e 28, possivelmente o céu estava claro, pois não houve precipitação. Pode-se observar que após a análise da direção dos ventos, estes prevalecem de leste e nordeste.

No dia 25 houve aumento na temperatura, potencializando que a pressão diminuísse e permitisse a entrada da Frente Polar Atlântica, que permaneceu até no dia 27, fazendo com que o município recebesse um nível elevado de precipitação no dia 26, chegando na faixa de $62.2 \mathrm{~mm}$, provocando assim enxurradas. 


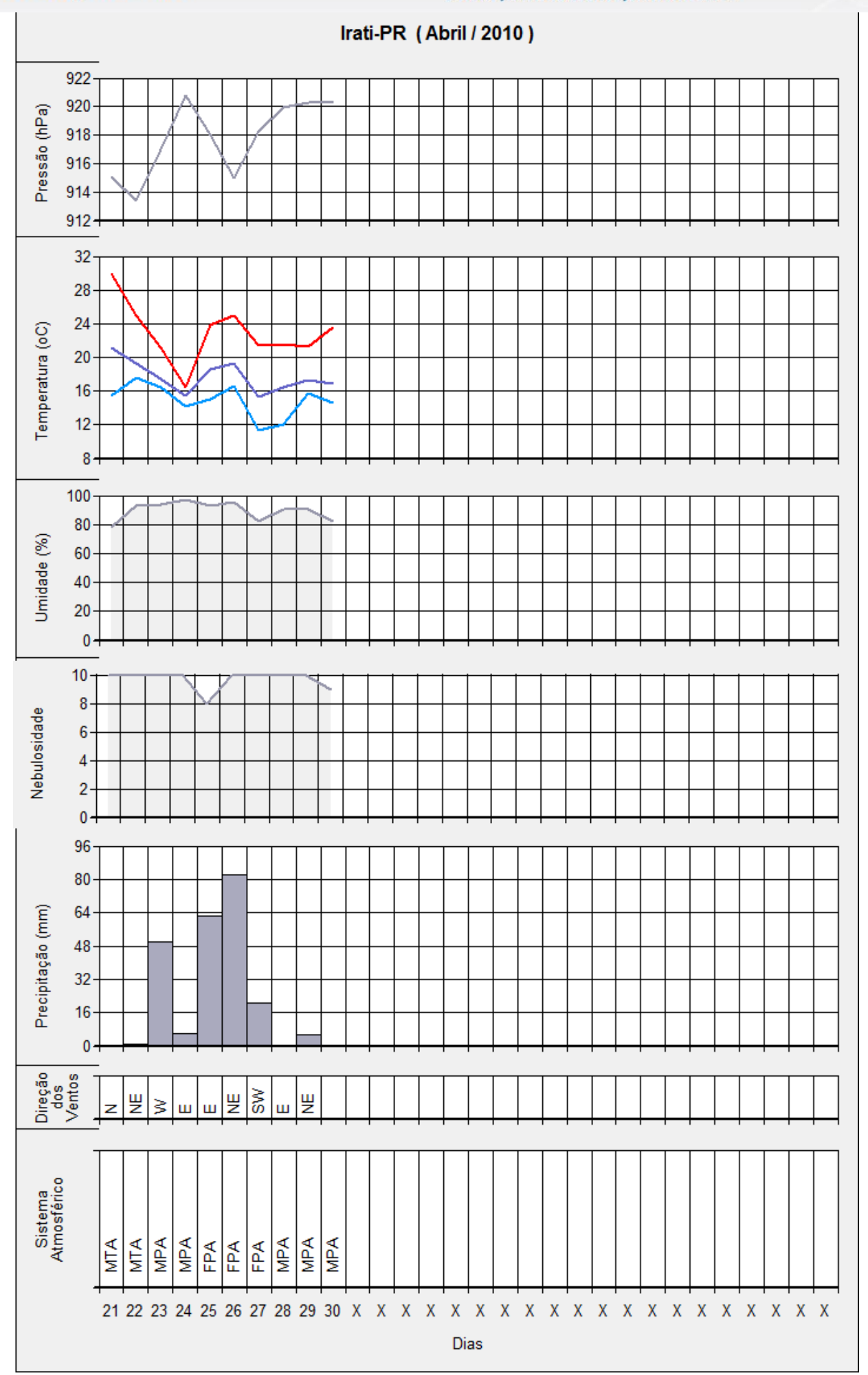

Figura 2 - evento hidrológico entre os dias 21 e 30 de abril de 2010. Figura com dados de Pressão atmosférica ao nível do mar (hPa), Temperatura mínima, média e máxima $\left({ }^{\circ} \mathrm{C}\right)$; umidade relativa do ar (\%); precipitação acumulada em 24h (mm); direção dos ventos e sistemas atmosféricos atuantes no dia (FPA: Frente Polar Atlântica, MPA: Massa

Polar Atlântica, MTA: Massa Tropical Atlântica), x: sem data. Fonte: Estação Meteorológica de Observação de Superfície Automática do INMET. Organizado por KRUK (2016). 
Este evento hidrológico foi classificado pela defesa civil como enxurrada, e ocorreu em julho de 2011, afetando cerca de 8.303 pessoas. Entre os dias 26 de julho a 4 de agosto houve um índice pluviométrico de 199.4 mm (Figura 3).

Os primeiros elementos atmosféricos analisados foram os de temperatura e pressão atmosférica. Onde no dia 26 a pressão se manteve elevada, e a temperatura se encontrava baixa. No dia 27 a pressão começa a diminuir, e a temperatura teve oscilações, permanecendo assim até no dia 30. Já no dia 31 a temperatura volta a diminuir, e a pressão aumenta. No dia 01 de agosto a pressão e a temperatura diminuem. Já no dia 03 a temperatura decai muito, fazendo com que a pressão aumente.

Depois se relaciona a temperatura, umidade relativa do ar e a pressão atmosférica. Constatou-se que a umidade relativa permanece baixa até o dia 29 , onde a temperatura passa a diminuir e a pressão aumenta. Do dia 30 até o dia 01 de agosto a pressão continua alta, enquanto a temperatura oscila, e a umidade se encontra alta. A partir do dia 02 a umidade diminui, chegando a $69 \%$, a temperatura diminui e a pressão aumenta.

Quanto à nebulosidade relacionada com a precipitação se constatou que entre os dias 26 a 29 o céu permaneceu claro. A partir do dia 30 até o dia 02 o céu passou a ficar encoberto. Já no dia 03 volta a ficar claro, pois não tem índice de precipitação.

Por meio da análise da direção dos ventos, se verificou que a direção predominante foram ventos de sul, nordeste e oeste. Esses que possivelmente trouxeram umidade para a região.

No dia 30 a máxima se encontrava na faixa de 18.6, considerada uma temperatura alta para a região no inverno, fazendo com que a pressão diminuísse e então houvesse a entrada da Frente Polar e também a sua permanência até o dia 2, provocando chuvas intensas no município. 


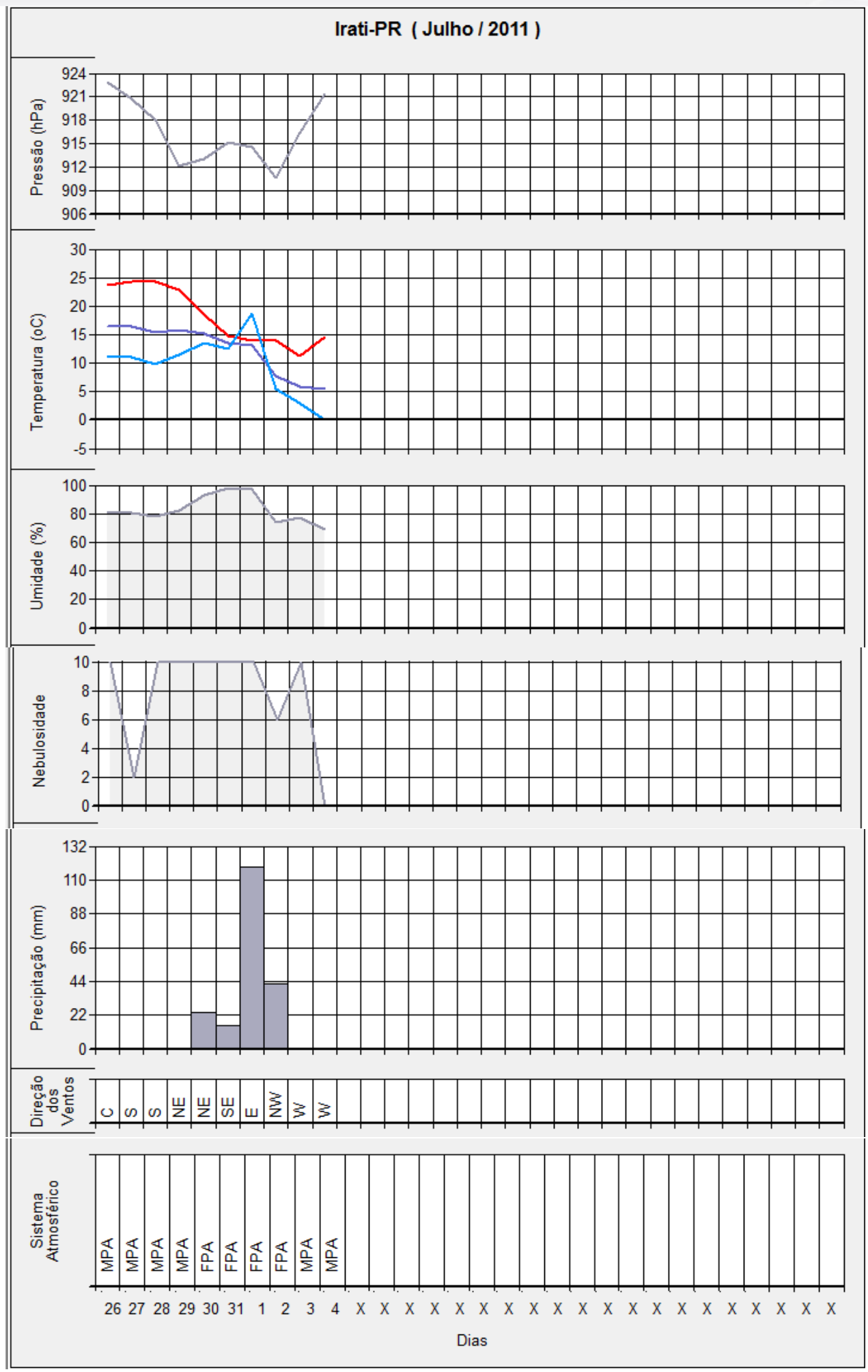

Figura 3 - evento hidrológico, entre os dias 26 de julho e 04 de agosto do ano de 2011. Figura com dados de Pressão atmosférica ao nível do mar (hPa), Temperatura mínima, média e máxima $\left({ }^{\circ} \mathrm{C}\right)$; umidade relativa do ar $(\%)$; precipitação acumulada em 24h (mm); direção dos ventos e sistemas atmosféricos atuantes no dia (FPA: Frente Polar Atlântica, MPA: Massa Polar Atlântica), x: sem data. Fonte: Estação Meteorológica de Observação de Superfície Automática do INMET. Organizado por KRUK (2016). 


\section{Conclusão}

Foram registradas diversas datas pela defesa civil, de 1983 até 2015, as quais, tiveram elevadas precipitações. Diversos foram os fatores envolvidos que provocaram as inundações e enxurradas no Município de Irati e que causaram transtornos, principalmente em áreas próximas aos rios.

Observou-se que agem na região três tipos sistemas atmosféricos sendo: Massa Tropical Atlântica, Massa Polar Atlântica e também a Frente Polar Atlântica.

O principal motivo que causou as elevadas precipitações no Município de Irati foi a ocorrência de chuvas convectivas, as quais têm como característica significativa intensidade em pouco tempo e também ocorreu as chuvas frontais, essas em que massas de ar quentes e frias se encontravam. Já no inverno o principal motivo era a atuação de uma Frente Polar Atlântica que, entrava na região devido ao aumento da temperatura, a qual, por consequência diminuía a pressão.

Desse modo, a análise rítmica possibilitou o entendimento da ocorrência dos fenômenos que provocaram, na maioria das datas, chuvas intensas e contínuas e que devido ao solo impermeabilizado e ausência de áreas verde a água infiltrou menos, então a mesma passou a escoar até os rios, provocando as enchentes e enxurradas.

Entendendo toda a dinâmica na região, passa a ser possível a geração de informações, as quais podem ser úteis para prever futuras enchentes colaborando para evitar transtornos que as precipitações intensas podem provocar ao município.

\section{Bibliografia}

ANDRADE, A.R. de; FELCHAK, I. M. A poluição urbana e o impacto na qualidade da água do Rio das Antas- IratiPr. Geoambiente n.12. Jataí-GO, | jan-jun/2009.

BORSATO, V. A.,A Participação dos sistemas atmosféricos atuantes na bacia do rio Paraná no período de 1980 a 2003. Tese (parcial), (Doutorado) Nupélia, Universidade Estadual de Maringá. Maringá, 2006.

BORSATO, V. A. BORSATO F. H, A dinâmica atmosférica e a influência da tropicalidade no inverno de 2007 em Maringá PR - Espacial.In: $8^{\circ}$ Simpósio Brasileiro de Climatologia Geográfica. Evolução Tecnológica e Climatologica. Universidade Federal de Uberlândia. Agosto 2008. Eixo 5 - Técnica em Climatologia - CD-ROM

CANAL, F. E. L. Estimativa de vazões de enchente em bacias hidrográficas do Espirito Santo com o uso do modelo HEC-HMS. 2011, 124 f. Trabalho de conclusão de curso (Graduando em Engenharia Ambiental) Universidade Federal do Espirito Santo. Vitória, 2011.

FREITAS, A. R. Análise do uso da terra e da artificialização do meio natural da bacia hidrográfica do Rio das Antas. In: Semana de Geografia de Irati: O ontem, o hoje e o amanhã: algumas reflexões sobre o espaço geográfico, VI, 2010, Irati, PR, Brasil. Anais. Irati: UNICENTRO, 2010. p. 129-162.

GEOGRAFALANDO. Clima. Massas de ar. Noções gerais. Disponível em:< http://geografalando.blogspot.com.br/2012/11/massa-de-ar-norcoes-gerais.html>. Acesso em: 22 de jul. de 2016

INMET. Projetos. Rede. Pesquisa. Disponível em: <http://www.inmet.gov.br/projetos/rede/pesquisa/. Acesso em: 07 de jan. de 2016. 
28 de Junho à 02 de Julho de 2017

Marinha do Brasil. DHN. Chm. Meteo. Prev. Cartas. Disponível em:<https://www.mar.mil.br/dhn/chm/meteo/prev/cartas/cartas.htm>. Acesso em: 07 de mar. De 2016.

MENDONÇA, D. S. de; SOUZA, F. C. R. de. Inundações:uma análise na perspectiva climatológica e urbana. Anais XVI Encontro Nacional dos Geógrafos. Crise, práxis e autonomia: espaços de resistência e de esperança. Espaço de Diálogo e Práticas. Porto Alegre, 2010, p. 9.

MONTEIRO, A. F. M. Análise Rítmica em Climatologia: São Paulo e chegas para um programa de Trabalho. Universidade de São Paulo. São Paulo, 1971.

TUCCI, C. E. M. Inundações e drenagem urbana. Cap. 3. p. 46-150.Disponível em: <http://www.agua.org.py/images/stories/biblioteca/subterraneas/carlos-tucci_inundaciones-y-drenajes-urbanos.pdf>. Acesso em: 20 de jul. de 2016. 